\title{
The Effect of the Family Case Management Program on 1996 Birth Outcomes in Illinois
}

\author{
KRISTIE KEETON, M.D., M.P.H., ${ }^{1}$ STEPHEN E. SAUNDERS, M.D., M.P.H., ${ }^{2}$ \\ and DAVID KOLTUN, Ph.D. ${ }^{2}$
}

\begin{abstract}
Objectives: The purpose of this study was to determine if birth outcomes for Medicaid recipients were improved with participation in the Illinois Family Case Management Program. Methods: Health program data files were linked with the 1996 Illinois Vital Records linked birth-death certificate file. Logistic regression was used to characterize the variation in birth outcomes as a function of Family Case Management participation while statistically controlling for measurable factors found to be confounders.

Results: Results of the logistic regression analysis show that women who participated in the Family Care Management Program were significantly less likely to give birth to very low birth weight infants (odds ratio $[O R]=0.86,95 \%$ confidence interval $[C I]=0.75,0.99$ ) and low birth weight infants $(O R=0.83, C I=0.79,0.89)$. For infant mortality, however, the adjusted $O R(O R=0.98, C I=0.82,1.17)$, although under 1 , was not statistically significant.

Conclusions: These results suggest that the Family Case Management Program may be effective in reducing very low birth weight and low birth weight rates among infants born to low-income women.
\end{abstract}

\section{INTRODUCTION}

A $\mathrm{N}$ ESTIMATED 28,237 INFANT DEATHS (deaths in the first year of life) were reported in the United States in 1996, corresponding to an infant mortality rate of 7.2 per 1000 births, the lowest ever recorded in the United States. Despite the decline, however, the low birth weight (LBW) rate (number of infants born weighing $<2500 \mathrm{~g}$ per 1000 births) reached $7.4 \%$ in 1996, the highest level reported since $1975 .^{1}$
Two key factors, the birth weight distribution and the weight-specific mortality rates (death rates for infants at a given weight), determine the infant mortality (IM) rate. The rapid decline in IM from 1970 until the mid-1980s was primarily due to the decline in neonatal mortality (death in the first 27 days of life), with only a moderate decrease in the LBW rate during this period. This decline has been attributed to the increased survival of LBW infants as a result of the introduction of neonatal intensive care ${ }^{2}$ and

\footnotetext{
${ }^{1}$ Departments of Obstetrics and Gynecology and Internal Medicine, University of Michigan Medical Center, Ann Arbor, Michigan.

${ }^{2}$ Office of Family Health, Department of Human Services, Springfield, Illinois.
} 
the expansion of regionalized perinatal systems. ${ }^{3}$

The rapid decline in the IM rate slowed in the late 1980s, although both the neonatal mortality rate and the postneonatal mortality rate (deaths from 28 to 364 days of life per 1000 live births) continued to decline. As the LBW rate increased during this same period, the declines in the IM rate can only be due to declines in weight-specific mortality rates, and this has been the case. Declines in both the neonatal and postneonatal mortality rates likely reflect two important developments, introduction of an effective treatment for respiratory distress syndrome and decrease in death from sudden infant death syndrome (SIDS). ${ }^{4}$

Although IM has declined for all racial groups, major disparities persist. The relative difference in IM between African Americans and whites has increased, primarily reflecting the difference in neonatal mortality rates. ${ }^{4}$ Higher neonatal mortality rates among African Americans reflect their higher proportion of LBW and very low birth weight VLBW $(<1500 \mathrm{~g})$ births. $^{5}$

IM due to disorders related to short gestation and LBW, second only to congenital anomalies as the leading cause of IM, exhibited the smallest decline since 1979 of the 10 leading causes of infant death. ${ }^{1}$ Furthermore, of the LBW infants who do survive, many suffer lifetime disabilities, such as blindness, mental retardation, and neurological disorders. ${ }^{6-8}$ Thus, prevention of short gestation and LBW is one of the most important challenges facing medicine and public health today.

LBW is a multifaceted problem and has been linked to a variety of interrelated factors, including race, age, level of education, maternal health, use or abuse of substances, and prenatal care. ${ }^{9}$ The collective evidence suggests that adequate prenatal care is associated with decreased LBW rates, but predominantly among infants who are carried to term. ${ }^{10}$ In order for prenatal care to reduce both intrauterine growth retardation (IUGR) and preterm birth, prenatal intervention must target potentially modifiable risk factors. Of the currently known risk factors for IUGR and preterm delivery, those most amenable to modification include (1) psychosocial (e.g., reduction or cessation of smoking), (2) nutritional (e.g., increasing prepregnancy weight and ensuring adequate weight gain during pregnancy), and (3) medical (e.g., reducing overall morbidity). ${ }^{10}$ Comprehensive prenatal care that includes case management is one possible method through which women can receive the services they need to address these factors and reduce their risk of having a LBW infant.

Studies evaluating comprehensive prenatal care case management programs for women on Medicaid have shown variable effects on birth outcomes. One study found improvement in birth outcomes statewide. ${ }^{11}$ Other studies demonstrated improvement in birth outcomes for subpopulations only-medically high-risk women, ${ }^{12}$ women on cash assistance only, ${ }^{13}$ and African American women only, ${ }^{14}$ whereas another study demonstrated no impact of comprehensive prenatal care case management services on birth outcomes. ${ }^{15}$ Content and implementation of these programs certainly vary from state to state and may even vary between sites within each state. Further evaluation of comprehensive prenatal care case management services is needed to validate these studies and to identify the program features that are associated with improved birth outcomes. $^{12}$

In the State of Illinois, IM and LBW are particularly pressing problems. In a country with an IM rate that is much higher than those of most developed nations, Illinois is consistently among those states with the highest rates in the country. The state reliably ranks at or near 43 and 37 of the 50 states in IM and LBW rates, respectively. ${ }^{16}$

In 1993, through the Medicaid eligibility expansions and federal funds for enhanced prenatal care services, Title V, and State general revenue funds, the Illinois Family Case Management Program was implemented. Family Case Management delivers case management services to Medicaid-eligible and medically indigent pregnant women, infants, and high-risk children across the state. This retrospective cohort study assesses the effects of the prenatal care component of the Family Case Management Program on birth outcomes in 1996 in the state of Illinois.

\section{MATERIALS AND METHODS}

\section{The Family Case Management Program}

Family Case Management services are provided to women and children through state contracts with local health departments, federally qualified health centers, and community-based organizations. The goals of the program are to 
provide access to healthcare, including prenatal care, pediatric primary care, family planning services, and specialty services; identify and resolve access barriers; and provide education. Women are recruited into the program through participation in other programs, including the Special Supplemental Nutrition Program for Women, Infants, and Children (WIC) and Medicaid, and through community outreach.

Once a woman decides to participate in the program, her needs are assessed by a case manager who has a bachelor's level degree (preferably, but not necessarily, in a health-related field). Assessment involves dialogue between the client and case manager to assess health, social, environmental, and educational needs, as well as access barriers. The case manager together with the client then develops an individual care plan, which focuses on the woman's areas of highest need. Through linkages with other programs and resources within the agencies themselves, case managers refer the clients to and provide them with needed services. Services are provided throughout the pregnancy and for up to 1-3 years after delivery. An emphasis is placed on followup, both in the home and in the Family Case Management office, with the hope that the women will adopt healthy behaviors during pregnancy and become skilled in seeking out resources within their communities.

\section{Data sources}

Three data sources were used to carry out this evaluation: (1) Cornerstone, Illinois' management information system for the Family Case Management and WIC programs, (2) the Medicaid Management Information System (MMIS), and (3) the 1996 Vital Records Master Birth File. These databases were linked as follows. First, to identify all women who participated in Family Case Management, Cornerstone files were matched to the 1996 Vital Records Master Birth File using a set of 20 variables, including the infant's first and last names, the date of delivery, and the mother's first and last names or maiden name. Next, using the same matching fields to identify all women with a hospital delivery claim paid for by Medicaid during calendar year 1996, the MMIS files were electronically linked to the previously linked Cornerstone-1996 Master Birth File. A matching rate of $98 \%$ was achieved for both steps. Next, all women on Medicaid with expected delivery dates in
1996, but still without a Medicaid paid hospital claim, were identified in MMIS and matched to the Vital Records Master Birth File. The Master Birth File was then linked to the Death Certificate File from the Matched Birth-Death Certificate File.

\section{Study population}

For the purposes of this study, birth outcomes for women participating in both the Medicaid and the Family Case Management programs $(42,683)$ were compared with the birth outcomes of women participating in the Medicaid program only $(31,982)$. Women with multiple births $(1,818)$ were excluded from the analysis. In addition, because women who give birth preterm have a reduced opportunity to participate in Family Case Management, women entering Family Case Management in their third trimester could potentially bias the results. Because of database limitations, however, we were not able to exclude women who entered Family Case Management in the third trimester. In an attempt to control for this potential bias, entry into prenatal care was used as a proxy for entry into Family Case Management. Therefore, all women who entered prenatal care in the third trimester were excluded from the analysis $(3,436)$. Finally, because women who had no prenatal care were also less likely to have participated in Family Case Management, they were also excluded from this analysis $(1,999)$.

\section{Variables}

Independent variable. Participation in Family Case Management, the independent variable, was defined for most clients by an active status in Cornerstone. Once a case manager successfully contacted a client, the client's existing Cornerstone file was activated, or an active Cornerstone file was created for her.

Outcome variables. The outcome variables in this study were VLBW ( $<1500 \mathrm{~g})$, LBW $(<2500 \mathrm{~g})$, and IM (death within the first year of life). These variables were identified through the Vital Records linked Birth-Death Certificate File.

Potentially confounding variables. Maternal variables known to influence birth outcomes were examined. These variables include (1) racial/ethnic group (African American, white, Hispanic), (2) marital status, (3) age ( $<20$ or $>34,20-34)$, (4) ed- 
ucation level ( $<12$ years, $\geq 12$ years), (5) cigarette smoking, (6) medical risk factors (complications of pregnancy and concurrent illnesses), (7) parity $(0-4,>4),(8)$ adequacy of prenatal care (adequate was defined using Kessner's adequate category; less than adequate is a combination of Kessner's intermediate and inadequate categories), and (8) participation in WIC. ${ }^{17}$ Although the prevalence of alcohol use among pregnant women has increased since $1991,{ }^{18}$ alcohol consumption was not examined as a risk factor because of poor selfreporting history on birth certificates. ${ }^{19,20}$ These variables were identified through the linked Vital Records Master Birth File and later through the linked Birth-Death Certificate File and Cornerstone.

\section{Statistical analysis}

Crude outcome rates were compared between Family Case Management and non-Family Case Management participants using chi-square tests. Then, potentially confounding variables were individually assessed for a relationship to the independent variable (Family Case Management) and each of the outcome variables (VLBW, LBW, IM) using chi-square tests. Variables found to be significantly associated with the independent variables or outcome variables were then included in a logistic regression analysis. Each logistic regression analysis assessed the effect of the Family Case Management program on a unique birth outcome while controlling for measurable risk markers.

\section{RESULTS}

Outcome measures in Table 1 reveal that the VLBW rate, the LBW rate, and the IM rate were all significantly lower among the women on Medicaid who participated in Family Case Management than among those who did not participate in Family Case Management. The birth outcomes are also shown separately for African American, Hispanic, unmarried, and teen clients, of whom all, with the exception of the IM rate among African Americans, had a significant decrease in the outcomes examined.

Table 2 shows the chi-square analysis for potential confounding variables. The numbers in Table 2 refer to percentages of participants and nonparticipants with certain potentially confounding variables. Women who participated in Family Case Management were less likely to be African American (i.e., approximately one half of

Table 1. Outcome Measures for All Medicaid Live Births by Presence of Family Case Management (FCM), Illinois, 1996a

\begin{tabular}{|c|c|c|c|c|}
\hline Outcome measures & $\begin{array}{c}\text { Participated in } \\
\text { FCM }\end{array}$ & $\begin{array}{c}\text { Did not } \\
\text { participate in FCM }\end{array}$ & $\%$ decrease & $\begin{array}{l}\mathrm{p} \text { value for } \\
\text { difference }\end{array}$ \\
\hline Total & $n=42,683$ & $n=31,982$ & & \\
\hline$\%<1500 \mathrm{~g}$ & 1.4 & 2.5 & 44 & $<0.05$ \\
\hline$\%<2500 \mathrm{~g}$ & 8.3 & 12.9 & 36 & $<0.05$ \\
\hline Infant deaths per 1000 live births & 7.9 & 11.8 & 33 & $<0.05$ \\
\hline African American & $n=10,795$ & $n=16,959$ & & \\
\hline$\%<1500 \mathrm{~g}$ & 2.5 & 3.1 & 19 & $<0.05$ \\
\hline$\%<2500 \mathrm{~g}$ & 13.0 & 16.2 & 20 & $<0.05$ \\
\hline Infant deaths per 1000 live births & 12.9 & 14.0 & 8 & \\
\hline Hispanic & $n=13,430$ & $n=7,096$ & & \\
\hline$\%<1500 \mathrm{~g}$ & 0.7 & 1.4 & 50 & $<0.05$ \\
\hline$\%<2500 \mathrm{~g}$ & 5.3 & 7.8 & 32 & $<0.05$ \\
\hline Infant deaths per 1000 live births & 5.5 & 7.6 & 28 & $<0.05$ \\
\hline Unmarried & $n=26,808$ & $n=23,581$ & & \\
\hline$\%<1500 \mathrm{~g}$ & 1.6 & 2.7 & 41 & $<0.05$ \\
\hline$\%<2500 \mathrm{~g}$ & 9.3 & 14.1 & 34 & $<0.05$ \\
\hline Infant deaths per 1000 live births & 8.8 & 12.8 & 31 & $<0.05$ \\
\hline$<20$ years of age & $n=11,040$ & $n=8,542$ & & \\
\hline$\%<1500 \mathrm{~g}$ & 1.5 & 2.3 & 35 & $<0.05$ \\
\hline$\%<2500 \mathrm{~g}$ & 8.7 & 12.0 & 39 & $<0.05$ \\
\hline Infant deaths per 1000 live births & 7.2 & 11.5 & 37 & $<0.05$ \\
\hline
\end{tabular}

${ }^{a}$ Includes multiple births and women with third trimester entry into prenatal care and no prenatal care. 
Table 2. Association of Participation in Family Case Management (FCM) with Potential Confounding Factors among Women with Singleton Medicaid Live Births, Illinois, $1996^{a}$

\begin{tabular}{lccc}
\hline $\begin{array}{l}\text { Potential confounding } \\
\text { factor }\end{array}$ & $\begin{array}{c}\text { Participated in } \\
\text { FCM } \\
(\%)\end{array}$ & $\begin{array}{c}\text { Did not participate } \\
\text { in FCM } \\
(\%)\end{array}$ & $\begin{array}{r}\text { p value for } \\
\text { difference }\end{array}$ \\
\hline African American & 24.6 & 52.0 & $<0.001$ \\
White & 73.4 & 46.3 & $<0.001$ \\
Hispanic & 31.3 & 22.7 & $<0.001$ \\
Unmarried & 62.4 & 72.7 & $<0.001$ \\
<20 years or $>34$ years of age $_{\text {Education }<12 \text { years }}{ }^{2}$ & 30.4 & 33.1 & $<0.001$ \\
Mother smoked & 42.7 & 42.1 & 0.389 \\
Medical risk factors this pregnancy & 20.1 & 17.6 & $<0.001$ \\
Parity $>4$ & 25.8 & 25.6 & 0.561 \\
Kessner index less than adequate & 9.4 & 15.9 & $<0.001$ \\
Did not participate in WIC & 37.7 & 42.2 & $<0.001$ \\
\hline
\end{tabular}

${ }^{\mathrm{a} E x c l u d i n g}$ births to mothers who had no prenatal care or entered prenatal care in the third trimester.

${ }^{\mathrm{b}}$ Not included in the logistic regression analysis.

nonparticipants were African American, and only one quarter of participants were African American), to be unmarried, to be $<20$ years or $>34$ years of age, to have had more than four births, to have less than adequate prenatal care, to have not participated in the WIC program and more likely to be white or Hispanic and to have smoked than the Medicaid recipients who did not participate in Family Case Management. No difference was found between the two groups in years of education or medical risk factors during pregnancy. Therefore, these factors were not included in the logistic regression analysis.

Adverse birth outcomes were assessed by potential confounding factors (Table 3). The VLBW and LBW rates were found to be significantly associated with all factors examined, with the exception of prenatal care adequacy and education, respectively. The IM rate was significantly associated with all factors examined, with the exception of maternal age. Only the factors found to be significantly associated with an adverse birth outcome were included in the logistic regression analysis for that outcome.

Table 4 presents the results of the logistic regression analysis. After controlling for those factors found to be significantly associated with either participation in Family Case Management or the birth outcome, not participating in WIC, smoking, and being African American were the strongest predictors of adverse birth outcomes among those factors examined. Women who participated in Family Case Management were found to be 0.86 times as likely to have had a
VLBW birth, 0.83 times as likely to have had an LBW birth, and 0.98 times as likely to have had an infant death. Confidence intervals for both the VLBW and LBW ORs did not include 1.00.

\section{DISCUSSION}

The results of this study suggest that Family Case Management participation improves birth outcomes among low-income women. In comparison with infants born to women not enrolled in Family Case Management, infants enrolled in Family Case Management weighed more and had a slightly, although not statistically significant, greater chance for survival. Taking into consideration the fact that IM is a rare event, the failure of this outcome measure to reach statistical significance may be due to insufficient power to detect a difference. Family Case Management appears to have the largest effect on the LBW rate. This is an important area for intervention, as infants weighing $<2500 \mathrm{~g}$ have a 40 times greater risk of neonatal death and 5 times greater risk of postneonatal death than do normal birth weight infants. ${ }^{3}$ These results, however, should be considered while keeping the limitations of the study in mind.

\section{Study limitations}

Selection bias. In a study such as this, in which it was not possible to randomize patients into treatment and control groups, there is a possibil- 
Table 3. Association of Participation in FCM with Potential Confounding Factors among Women with Singleton Medicaid Live Births, Illinois, 1996a

\begin{tabular}{|c|c|c|c|}
\hline $\begin{array}{l}\text { Potential confounding } \\
\text { factor }\end{array}$ & $\begin{array}{c}\text { Very low } \\
\text { birth weight rate (\%) }\end{array}$ & $\begin{array}{c}\text { Low birth weight } \\
\text { rate }(\%)\end{array}$ & $\begin{array}{c}\text { Infant mortality rate } \\
\text { (per 1000) }\end{array}$ \\
\hline \multicolumn{4}{|l|}{ Race/ethnicity } \\
\hline African American & 2.2 & 12.5 & 11.8 \\
\hline White & 1.0 & 6.3 & 6.9 \\
\hline Hispanic & 0.9 & 5.3 & 6.7 \\
\hline \multicolumn{4}{|l|}{ Marital status } \\
\hline Single & 1.7 & 9.7 & 9.7 \\
\hline Married & 1.1 & 6.2 & 6.6 \\
\hline \multicolumn{4}{|l|}{ Age (years) } \\
\hline$<20$ and $>34$ & 1.7 & 9.9 & $8.9^{*}$ \\
\hline $20-34$ & 1.4 & 7.9 & $8.6^{*}$ \\
\hline \multicolumn{4}{|l|}{ Education (years) } \\
\hline$<12$ & 1.4 & $8.6^{*}$ & 9.6 \\
\hline$\geq 12$ & 1.6 & $8.5^{*}$ & 8.0 \\
\hline \multicolumn{4}{|l|}{ Smoking status } \\
\hline Mother smoked & 1.8 & 13.4 & 11.7 \\
\hline Mother did not smoke & 1.4 & 7.4 & 8.0 \\
\hline \multicolumn{4}{|c|}{ Medical risk factors this pregnancy } \\
\hline Present & 3.5 & 15.7 & 14.5 \\
\hline Absent & 0.8 & 6.1 & 6.7 \\
\hline \multicolumn{4}{|l|}{ Parity } \\
\hline $0-4$ & 1.4 & 8.0 & 8.1 \\
\hline$>4$ & 1.9 & 12.3 & 13.2 \\
\hline \multicolumn{4}{|l|}{ Kessner index } \\
\hline Adequate & $1.4^{*}$ & 7.5 & 7.5 \\
\hline Less than adequate & $1.5^{*}$ & 10.2 & 10.6 \\
\hline \multicolumn{4}{|l|}{ WIC participation } \\
\hline Did not participate & 2.4 & 11 & 12.4 \\
\hline Participated & 1.1 & 7.4 & 7.0 \\
\hline
\end{tabular}

aExcluding births to mothers who had no prenatal care or entered prenatal care in the third trimester.

*All differences are significant to the 0.05 level with the exception of those values with an asterisk $(*)$. Factors not found to be significantly associated with an adverse outcome were not included in the logistic regression analysis for that outcome.

ity of selection bias. Participants in Family Case Management appear to be at lower risk with respect to several factors, such as race, marital status, age, and WIC participation. One source of se- lection bias may have resulted from the methods of recruitment.

Women were recruited into the program by two methods, through the Department of Public

Table 4. Adjusted ORs (95\% CIs) for Adverse Birth Outcomes by Presence of Confounding Factors for Singleton Medicaid Live Births, Illinois, $1996^{a}$

\begin{tabular}{lccc}
\hline Risk factor & $\begin{array}{c}\text { Very low } \\
\text { birth weight }\end{array}$ & Low birth weight & Infant mortality \\
\hline African American & $1.71(0.99,2.94)$ & $1.43(1.14,1.79)$ & $1.33(0.67,2.63)$ \\
White & $0.94(0.54,1.62)$ & $0.75(0.60,0.94)$ & $0.87(0.44,1.72)$ \\
Hispanic & $0.80(0.65,0.98)$ & $0.94(0.86,1.03)$ & $1.03(0.80,1.31)$ \\
Unmarried & $1.17(1.00,1.34)$ & $1.14(1.07,1.22)$ & $1.21(0.99,1.48)$ \\
$<20$ and $>34$ years of age & $1.25(1.09,1.43)$ & $1.24(1.17,1.31)$ & \\
Mother smoked & $1.25(1.06,1.46)$ & $1.97(1.85,2.11)$ & $1.44(1.17,1.76)$ \\
Parity $>4$ & $1.11(0.93,1.33)$ & $1.23(1.14,1.33)$ & $1.31(1.05,1.64)$ \\
Less than adequate Kessner & $2.25(1.97,2.56)$ & $1.78(1.66,1.91)$ & $1.25(1.08,1.48)$ \\
Did not participate in WIC & $0.86(0.75,0.99)$ & $1.44(1.36,1.53)$ & $1.73(1.46,2.05)$ \\
$\quad$ Family Case Management & $0.83(0.79,0.89)$ & $0.98(0.82,1.17)$ \\
\hline
\end{tabular}

${ }^{a}$ Excluding births to mothers who had no prenatal care or entered prenatal care in the third trimester. 
Aid and by community outreach. The Department of Public Aid periodically downloaded names of all known pregnant women on Medicaid from the MMIS into Cornerstone, the management information system for Illinois' WIC and Family Case Management programs. This method of outreach was very effective in reaching women who became eligible for Medicaid by becoming pregnant through the Medicaid expansion. Many women, however, were on Medicaid before becoming pregnant. Although the latter, who were often Temporary Assistance to Needy Families (TANF) recipients as well, were required to meet with their caseworkers every 6 months, the caseworkers may not have inquired routinely about pregnancy status. As only those files of women both on Medicaid and known to be pregnant were downloaded into Cornerstone, many pregnant women on TANF were missed. These women are potentially the most at risk for adverse pregnancy outcomes. Data from the Illinois Department of Human Services reveal that in June of $1996,45 \%$ of TANF recipients were African American compared with 39\% who were white and $15 \%$ who were Hispanic. This may help account for the fact that a large proportion of the nonparticipants were African American. Furthermore, there is a group of women who were not on Medicaid until after delivery. These women were either unaware of their eligibility or became eligible for Medicaid only after incurring hospital expenses by giving birth. Thus, the non-Family Case Management participants were largely women who received TANF as well as women who spent down to Medicaid eligibility, whereas Family Case Management participants consisted mostly of women who were eligible for Medicaid through the Medicaid expansion by becoming pregnant.

Although participants were at lower risk for several risk factors, the effect of Family Case Management participation remained after adjustment for risk factors in the logistic regression model. Even though we compared outcomes among Medicaid recipients only, Family Case Management participants and nonparticipants may differ in ways not measured in this study. We controlled for several measurable sociodemographic and behavioral characteristics, but differences in other unmeasureable characteristics could have biased our findings. Women who participated in Family Case Management may have been more willing to seek services, more recep- tive to recommendations of healthcare providers, more likely to adopt healthful behaviors and may have had more resources.

Database limitations. Limitations exist in the databases used in this evaluation. In 1996, there were shortcomings in the management information system that may have underestimated the effects of Family Case Management. First, prior to 1997, two management information systems were used in Illinois, the Cornerstone system, used statewide, and a non-Cornerstone system, used only in Chicago. When the two systems were merged in 1996 to create a single statewide system, some of the women in the non-Cornerstone file with inactive statuses were inadvertently given active statuses. Therefore, women whose files were downloaded from Public Aid into Chicago's non-Cornerstone management information system but were never successfully contacted by a case manager became active when the two systems were merged. Although we are unable to accurately estimate the number of misclassified women, we know that it is $<5000$. This differential misclassification bias may have underestimated the effect of our intervention.

Second, because neither the trimester in which participation was initiated nor the number of successful visits were recorded in Cornerstone as of 1996, we were not able to assess a dose-response. This may have resulted in an underestimation of the effect of Family Case Management on birth outcomes, as women with only one successful contact are included in the intervention group.

Lastly, since birth certificate data were crucial to this analysis, limitations of this database are relevant to this study. Studies of the accuracy of birth certificate variables suggest that reporting is very accurate for birth weight, fair to good for tobacco use and prenatal care, and poor for medical history and alcohol use. ${ }^{19,20}$

Nonuniformity of intervention. This study is also limited in its inability to control for variability in the intervention. Because the Family Case Management program is implemented through a variety of sites (local health departments, federally qualified health centers, and community-based organizations), the intervention is not entirely uniform. Although each case manager has guidelines to follow, it may be impossible to meet these guidelines in every case because of extenuating circumstances, such as attrition or late enrollment 
into the program. Until the uniformity of intervention can be accurately assessed, this will remain a limitation for any Family Case Management evaluation.

Preterm delivery bias. The only criterion for inclusion in the intervention group was an active case management status in Cornerstone, which is defined by at least one successful contact between the Family Case Management agency and the client. The successful contact could have been made at any time during the pregnancy. Because a woman can enter the Family Case Management program at any time during her pregnancy, preterm delivery bias is also a limitation of this study. Premature delivery results in a reduced opportunity for participation in Family Case Management. Because women who deliver preterm have less opportunity to participate in Family Case Management than women who deliver at term, women entering the program late in their pregnancies may have created a spurious relationship between participation in Family Case Management and improved birth outcomes, overestimating our results. We attempted to control for this by excluding from the analysis all women who either entered prenatal care in the third trimester or received no prenatal care.

\section{Recommendations}

In order to see a maximum effect of Family Case Management, some improvements need to be made. First, efforts to identify pregnant TANF (formerly AFDC) recipients early in their pregnancy must be improved. The earlier the women are identified and the earlier their information is downloaded into Cornerstone from the MMIS, the earlier a Family Case Management case manager can contact them about the program. Second, improvements in outreach and case finding need to be made to identify the non-TANF Medicaid recipients eligible to participate in Family Case Management. Third, although a higher proportion of women in Family Case Management also participated in the WIC program than those not in Family Case Management (77.8\% vs. $53.9 \%$ ), we need to improve service integration to ensure that all nutritionally at-risk pregnant women who are participating in Family Case Management are also participating in WIC, and vice versa.

Further evaluation of comprehensive prenatal care case management services is needed to validate this study and to identify the program features that are associated with improved birth outcomes. One such feature of the program may be the increased participation of the intervention group in the WIC program. Women who participated in Family Case Management were significantly more likely to also participate in the WIC program, consistent with the findings in North Carolina's Baby Love Program. ${ }^{11}$ This is important for three reasons. First, previous studies have suggested that WIC participation alone improves birth outcomes. ${ }^{21,22}$ Second, participation in both programs seems to have a synergistic effect on birth outcomes (Illinois Department of Human Services, unpublished observations). Third, because it is the goal of the Family Case Management program to assist women in navigating the services available to them, increased WIC participation is just one example of the impact this type of assistance can have.

\section{CONCLUSIONS}

LBW and IM are serious problems in both the state of Illinois and the United States. Evidence has shown that routine access to traditional prenatal care is not enough to address the confluence of social, economic, and healthcare factors associated with poor birth outcomes. Low-income women must have their basic housing, nutrition, healthcare, and transportation needs met, as well as their need for traditional prenatal care. The Family Case Management Program may assist low-income pregnant women in meeting these needs. This study suggests that Family Case Management may be effective in improving birth outcomes among low-income women through enhanced prenatal care services.

\section{REFERENCES}

1. Guyer B, Martin JA, MacDorman MF, Anderson RN, Strobino DM. Annual summary of vital statistics1996. Pediatrics 1997;100:905.

2. Lee KS, Paneth N, Gartner LM, Pearlman MA. Neonatal mortality: An analysis of the recent improvement in the United States. Am J Public Health 1980;70:15.

3. McCormick MC. The contribution of low birthweight to infant mortality and childhood morbidity. N Engl J Med 1985;312:82. 
4. Singh GK, Yu SM. Infant mortality in the United States: Trends, differentials, and projections, 1950 through 2010. Am J Public Health 1995;85:957.

5. Guyer B. Medicaid and prenatal care: Necessary but not sufficient. JAMA 1990;264:2264.

6. Overpeck MD, Moss AJ, Hoffman HJ, Hendershot GE. A comparison of the childhood health status of normal birthweight and low birthweight infants. Public Health Rep 1989;104:59.

7. Stanley FJ. Survival and cerebral palsy in low birthweight infants: Implications for perinatal care. Paediatr Perinat Epidemiol 1992;6:298.

8. Roussonouis SH, Hobley PA, Dear PR. Five-year follow-up of very low birthweight infants: Neurological and psychological outcome. Child Care Health Dev 1993;19:426.

9. Poland ML, Ager JW, Olson KL, Sokal RJ. Quality of prenatal care: Selected social, behavioral, and biomedical factors and birthweight. Obstet Gynecol 1990;75:607.

10. Alexander GR, Korenbrot CC. The role of prenatal care in preventing low birth weight. Future Child 1995;5:103.

11. Buescher PA, Roth MS, Willaims A, Goforth CM. An evaluation of the impact of maternity care coordination on Medicaid birth outcomes in North Carolina. Am J Public Health 1991;81:1625.

12. Baldwin LM, Larson EH, Connell FA, et al. The effect of expanding Medicaid prenatal services on birth outcomes. Am J Public Health 1998;88:1623.

13. National Technical Information Service. Impact of Medicaid changes on infant health in New York City. Springfield, VA: US Department of Commerce, 1997.

14. Reichman NE, Florio MJ. The effects of enriched prenatal care services on Medicaid birth outcomes in New Jersey. J Health Econ 1996;15:455.

15. Piper JM, Mitchel EF, Ray WA. Evaluation of a program for prenatal care case management. Fam Plann Perspect 1996;28:65.
16. March of Dimes Birth Defects Foundation. Summary rankings, 1995-1997 averages. Accessed March 28, 2001, at www.modimes.org/HealthLibrary2/Infant HealthStatistics/PerinatalProfiles/Profiles.htm

17. Kessner DM, Singer J, Kalk CD, Schlesinger ER. Contrasts in health status. Infant death: An analysis of maternal risk and health care. Washington, DC: Institute of Medicine, National Academy of Sciences, 1973, vol 1.

18. Abraham SH, Lumna ET, Floyd RL, Murphy CC, Bennett EM, Boyle CA. Alcohol consumption by pregnant women in the United States during 1988-1995. Obstet Gynecol 1998;92:187.

19. Buescher PA, Taylor KP, Davis MH, Bowling JM. The quality of the new birth certificate data: A validation study in North Carolina. Am J Public Health 1993; 83:1163.

20. Piper JM, Mitchel EF, Snowden M, Hall C, Adams M, Taylor P. Validation of 1989 Tennessee birth certificates using maternal and newborn hospital records. Am J Epidemiol 1993;136:758.

21. Ahluwalia IB, Hogan VK, Grummer-Strawn L, Colville WR, Peterson A. The effect of WIC participation on small-for-gestational-age births: Michigan, 1992. Am J Public Health 1998;88:1374.

22. Abrams B. Preventing low birth weight: Does WIC work? A review of the Special Supplemental Food Program for Women, Infants, Children. Ann NY Acad Sci 1993;678:307.

Address reprint requests to: Kristie Keeton, M.D., M.P.H. Robert Wood Johnson Clinical Scholars Program University of Michigan 6312 Medical Science I

1150 West Medical Center Drive Ann Arbor, MI 48109-0604 E-mail: kristie@umich.edu 